\title{
Drugs from Natural Substances: Why Study Them in Cerebral Infarction
}

\author{
Marie-Germaine Bousser \\ Neurology Department, Lariboisière Hospital and Paris Diderot University, Paris, France
}

The CHIMES trial [1], comparing a product from traditional Chinese medicine (TCM) and a placebo in patients with cerebral infarction, has already recruited 1,100 patients and is nearly completed. Over the 5 years it has been running, every time its protocol was presented at neurology or stroke meetings by one of the investigators it was met with a mixture of interest, skepticism and sometimes aggressiveness. Yet there are at least two good reasons to keep an open mind towards studying products from natural substances in cerebral infarction: the first is the constant failure of neuroprotective agents in this frequent worldwide condition which remains devastating despite treatments presently available; the second is the remarkable number of drugs coming from natural substances that are effective in other human diseases.

Among the many treatments that have been studied over the last 30 years in patients with cerebral infarction, four so far have an evidence-based efficacy: Stroke Unit care, intravenous rt-PA thrombolysis in the first $4.5 \mathrm{~h}$, aspirin and, in the few patients with malignant middle cerebral artery infarction, hemicraniectomy. However, the vast majority of trials have in fact been devoted to a different approach, namely neuroprotection, the aim of which is to 'antagonize the injurious biochemical and molecular events that eventuate in irreversible ischemic injury' [2]. In his 2008 review, Ginsberg [2] found 120 completed trials of neuroprotection for ischemic stroke, of which only one third were phase II or III trials involving over 200 subjects. His review and many others have extensively discussed why so many different drugs were found effective in animal models of acute brain ischemia and even sometimes in phase II trials in humans, but so far never in large phase III randomized clinical trials (RCT) [3-5]. Whatever the reasons - too narrow biochemical target of drugs, poor or insufficient preclinical data, inadequate methodology of clinical trials, etc. - the fact is that so far all neuroprotective drugs, including calcium channel blockers, NMDA antagonists, AMPA antagonists, GABA antagonists, antioxidants, magnesium, $\mathrm{NO}$-signal transduction down-regulators, leukocytes inhibitors, etc., have failed to decrease mortality and disability in patients with cerebral infarction. Much hope had been raised, for example, by compound NXY-059, a free radical spin trap, which had very impressive preclinical data $[6,7]$ : it was effective at both reducing infarct size and improving functional outcome in rodent and primate models of cerebral infarction and its efficacy was stronger than that of other neuroprotective drugs studied in the same models. Optimism was reinforced after the results of the first phase III RCT, 'SAINT I', based on 1,699 subjects, which showed a reduced disability at 90 days [8]. However, this was not confirmed in the larger SAINT II trial based on 3,306 patients which was entirely negative [9]. Reasons for this failure have again been widely dis-

\begin{tabular}{ll}
\hline KARGER & $\begin{array}{l}\text { (c) 2013 S. Karger AG, Basel } \\
\text { 1015-9770/13/0357-00IV\$38.00/0 Open cacess }\end{array}$ \\
E-Mail karger@karger.com & $\begin{array}{l}\text { This is an Open Access article licensed under the terms of } \\
\text { the Creative Commons Attribution-NonCommercial-No- } \\
\text { www.karger.com/ced }\end{array}$ \\
$\begin{array}{l}\text { Derivs 3.0 License (www.karger.com/OA-license), applica- } \\
\text { ble to the online version of the article only. Distribution for } \\
\text { non-commercial purposes only. }\end{array}$
\end{tabular}

Prof. M.G. Bousser

Lariboisière Hospital

2 rue Ambroise Paré

FR-75010 Paris (France)

E-Mail mg.bousser@lrb.aphp.fr 
cussed $[2,10]$ and might include a suboptimal biochemi$\mathrm{cal}$ and physicochemical profile of the drug, a longer window treatment $(6 \mathrm{~h})$ compared with that of studies in animals [2], and a too narrow effect on the ischemic cascade [10]. One of the most extensively studied drugs is the phospholipid precursor, citicoline (CDP-choline), which, on top of its neuroprotective effect, increases endogenous neuronal plasticity [11]. Many studies and meta-analyses have been performed over 2 decades with this drug and an increase in the probability of complete recovery at 3 months has been found in a pooled analysis of 1,652 patients [12]. Unfortunately, once again, the largest RCT so far, 'ICTUS' [13], based on 2,298 patients, failed to show a benefit and was actually stopped for futility after analysis of complete data from 2,078 patients.

The accumulation of these negative results has led to a widespread pessimism about neuroprotection and, more generally, about the development of new drugs to treat cerebral infarction other than new thrombolytics such as desmoteplase [14] or tenecteplase [15], or drugs that are able to increase thrombolysis such as antiplatelet agents and antithrombin drugs. Indeed, given the failure of the classical approach from molecular targets to animal models and to clinical trials in humans, many pharmaceutical companies have decided to stop all their research in acute stroke treatment.

Facing this situation, and rather than be resigned to this dreadful condition, there is little to lose by trying a different and somewhat reverse approach consisting of turning to products from natural substances that have been widely used in traditional medicines and then studying them in parallel, both in RTC in humans to assess their efficacy and in experimental models in vitro and in vivo to understand their putative mode of action. This is what has been done with NeuroAiD, a TCM compound officially registered in China in 2001 as a drug to facilitate stroke recovery at chronic stage. It has recently been shown to have potent protective effects in vitro and in vivo against focal and global ischemia in the rat and it also has a potent action to stimulate neurogenesis in vivo and in vitro $[16,17]$. Whether this beneficial effect will translate in humans when initiated during the acute stage within $72 \mathrm{~h}$ remains an open question until the results of CHIMES [1] and other large trials are available.

The majority of the world population is still using plant [18] or animal products [19] from traditional medicine as means of therapy, but Western medicine physicians are frequently unaware that many of the effective drugs they use also come from plants. This is the case, for instance, for the most widely used drug in the whole world, i.e. aspirin, which comes from the willow tree and the meadowsweet flower; salicylic acid, the first compound extracted, was later synthesized and, in 1897, acetylated to become acetyl-salicylic acid [20]. Over $130 \mathrm{im}$ portant drugs currently used in Western medicine come from plants, encompassing all fields of medicine including infectious disorders, cardiovascular diseases, neurological diseases such as epilepsy, cancers, etc. [18, 21-23]. Over $50 \%$ of anticancer drugs are somehow related to plants or even directly synthesized from them, such as vinblastine and vincristine isolated from Catharantus roseus, or paclitaxel (Taxol) derived from the bark of the Pacific yew tree, Taxus brevifolia [23]. Advantages and disadvantages of using plants as starting points for drug development have been extensively discussed but, given the astronomical price of the classical drug development, there is a rising interest in looking into substances used in traditional medicines which, furthermore, have at least the usual advantage of low human toxicity. TCM is the oldest and most developed of all traditional medicines and, although the substances used were not evaluated according to the Western medical standards, it is raising a growing interest, as illustrated by a recent critical review of 10 years (2000-2009) of original research reports published in the Chinese Medical Journal evaluating TCM and other natural products [24]. In summary, in a condition such as cerebral infarction, which remains both so frequent and so severe despite recent advancements in preventive and acute treatment, let us consider drugs from natural substances with a reasonable mixture of open-mindedness and scientific skepticism!

\section{Disclosure Statement}

M.-G.B. received travel support from Moleac for meetings of the CHIMES investigators. The Lariboisière neurology department received an annual research grant from Moleac.
References
1 Venketasubramanian N, Chen CLH, Gan RN, et al, CHIMES Investigators: A double-blind, placebo-controlled, randomized, multicenter study to investigate Chinese Medicine Neu- roAiD Efficacy on Stroke recovery (CHIMES Study). Int J Stroke 2009;4:54-60.
- Ginsberg MD: Neuroprotection for ischemic stroke: past, present and future. Neurophar- macology 2008;55:363-389.
3 Muir KW: Why have neuroprotectants failed? Lessons learned from stroke trials. J Neurol 2005;252:1011-1020. 
4 Faden AI, Stoica B: Neuroprotection. Challenges and opportunities. Arch Neurol 2007; 64:794-800.

$\checkmark 5$ Crossley NA, Sena E, Goehler J, et al: Empirical evidence of bias in the design of experimental stroke studies. A metaepidemiologic approach. Stroke 2008;39:929-934.

$\checkmark 6$ Hess DC: NXY-059. A hopeful sign in the treatment of stroke. Stroke 2006;37:26492650.

$\checkmark 7$ Fischer M: NXY-059 for acute ischemic stroke. The promise of neuroprotection is finally realized? Stroke 2006;37:2651-2652.

$>8$ Lees KR, Zivin JA, Ashwood T, et al, StrokeAcute Ischemic NXY treatment (SAINT I) Trial Investigators: NXY-059 for acute ischemic stroke. N Engl J Med 2006;354:588-600.

$>9$ Shuaib A, Lees KR, Lyden P, et al, SAINT II Trial Investigators: NXY-059 for the treatment of acute ischemic stroke. N Engl J Med 2007;357:562-571.

10 Savitz SI, Fisher M: Future of neuroprotection for acute stroke: in the aftermath of the SAINT trials. Ann Neurol 2007;61:396-402.

11 Hurtado O, Lizasoain I, Moro MA: Neuroprotection and recovey. Recent data at the bench on citicoline. Stroke 2011;42(suppl 1):S33-S35.
12 Davalos A, Castillo J, Alvarez-Sabin J, et al: Oral citicoline in acute ischemic stroke; an individual patient data pooling analysis of clinical trials. Stroke 2002;33:2850-2857.

13 Davalos A, Alvarez-Sabin J, Castillo J, et al, International Citicoline Trial on Acute Stroke (ICTUS) Trial Investigators: Citicoline in the treatment of acute ischaemic stroke: an international, randomised, multicentre, placebocontrolled study (ICTUS) trial). Lancet 2012; 380:349-357.

14 Hacke W, Furlan AJ, Al-Rawi Y, et al: Intravenous desmoteplase in patients with acute ischaemic stroke selected by MRI perfusiondiffusion weighted imaging or perfusion CT (DIAS-2). A prospective, randomized, double-blind, placebo-controlled study. Lancet Neurol 2009;8:141-150.

15 Parsons M, Spratt N, Bivard A, et al: A randomized trial of tenecteplase versus alteplase for acute ischemic stroke. N Engl J Med 2012; 366:1099-1107.

16 Quintard H, Borsotto M, Veyssiere J, et al: MLC901, a traditional Chinese medicine protects the brain against global ischemia. Neuropharmacology 2011;61:622-631.

17 Heurteaux C, Gandin C, Borsotto C, et al: Neuroprotective and neuroproliferative activities of NeuroAid (MLC601, MLC901), a Chinese medicine, in vitro and in vivo. Neuropharmacology 2010;58:987-1001.
8 Fabricant DS, Farnsworth NR: The value of plants used in traditional medicine for drug discovery. Environ Health Perspec 2001; 109(suppl 1):69-75.

19 Alves RR, Rosa LL: Why study the use of animal products in traditional medicines? J Ethnobiol Ethnomed 2005;1:5.

20 Fuster V, Sweeny JM: Aspirin: a historical and contemporary therapeutic overview. Circulation 2011;123:768-778.

21 Sutter MC, Wag YX: Recent cardiovascular drugs from Chinese medicinal plants. Cardiovasc Res 1993;27:1891-1901.

22 Kumar S, Madaan R, Bansal G, Jamwal A, Sharma A: Plants and plant products with potential anticonvulsant activity - a review. Pharmacog Commun 2012;2(suppl 1):3-99.

23 Mehndiratta S, Kumar S, Kumar Meena A, Koul S, Suri OP, Dhar KL: A review on plants - a useful source of anti-cancer drugs. J Pharm Res 2011;4264-271.

24 Collins RA: A ten-year audit of traditional Chinese medicine and other natural product research published in the Chinese Medical Journal (2000-2009). Chin Med J (Engl) 2011; 124:1401-1408. 